\title{
Identification of data-driven Dutch dietary patterns that benefit the environment and are healthy
}

\author{
Sander Biesbroek $^{1}$ (D) - W. M. Monique Verschuren ${ }^{1,2}$. \\ Yvonne T. van der Schouw ${ }^{2}$ - Ivonne Sluijs ${ }^{2}$. \\ Jolanda M. A. Boer ${ }^{1}$ Elisabeth H. M. Temme ${ }^{1}$
}

Received: 7 June 2017 / Accepted: 28 January 2018 /Published online: 16 February 2018

(C) The Author(s) 2018. This article is an open access publication

\begin{abstract}
More sustainable dietary patterns are needed to mitigate global warming. This study aims to identify data-driven healthy dietary patterns that benefit the environment. In EPIC-NL, diet was assessed using a 178-item FFQ in 36,203 participants aged 20-70 years between 1993 and 1997. The Dutch Healthy Diet index 2015 (DHD15-index) was used to score healthiness of the diet. As proxy for environmental impact, greenhouse gas (GHG) emissions were calculated using life cycle analysis. To determine patterns that are both healthy and environmentally friendly, reduced rank regression was applied. A "Plant-based Pattern" characterized by high consumption of fruits, vegetables, and legumes, and low consumption of fries, red meat, and processed meat and a "Dairy-based Pattern" characterized by high consumption of dairy, and nuts and seeds and low consumption of coffee and tea, sugar-containing sodas, lowfiber bread, and savory sauces were derived. At equal energy intake, the diet of adherents (highest quartile) to the "Plant-based Pattern" were significantly healthier (89.8 points on the DHD15-index, $p<0.0001)$ and more sustainable $\left(3.96 \mathrm{~kg} \mathrm{CO}_{2}\right.$-eq/day, $\left.p<0.0001\right)$ compared to the average diet (76.2 points, $4.06 \mathrm{~kg} \mathrm{CO}_{2}$-eq/day), whereas the "Dairy-based Pattern" was somewhat healthier $(77.9$ points, $p<0.0001)$, but less sustainable $\left(4.43 \mathrm{~kg} \mathrm{C} 0_{2}\right.$-eq/day, $p<0.0001)$. When deriving dietary patterns based on health and environmental aspects of the diets, a "Plant-based" and a "Dairy-based" pattern were observed in our study population. Of these, the plant-based diet benefits health as well as the environment.
\end{abstract}

Last names for indexing: Biesbroek, Verschuren, van der Schouw, Sluijs, Boer, and Temme.

Electronic supplementary material The online version of this article (https://doi.org/10.1007/s10584-0182153-y) contains supplementary material, which is available to authorized users.

Sander Biesbroek

sander.biesbroek@ rivm.nl

1 Centre for Nutrition, Prevention and Health Services, National Institute for Public Health and the Environment (RIVM), Antonie van Leeuwenhoeklaan 9, Bilthoven 3721 MA, The Netherlands

2 Julius Center for Health Sciences and Primary Care, University Medical Center Utrecht, Universiteitsweg 100, 3584 CG Utrecht, The Netherlands 


\section{Background}

The Paris Climate Agreement and the United Nations Sustainable Development Goals underline the need to improve the sustainability of our society and limit global warming to less than $2{ }^{\circ} \mathrm{C}$ (United Nations 2015; United Nations General Assembly 2015). Excessive greenhouse gas (GHG) emissions are an important driver of climate change and new strategies are needed to reduce emissions (Moss et al. 2010). Food and beverage consumption is estimated to be responsible for $20-30 \%$ of total GHG emissions in the EU, and thus have a major impact on the environment (Tukker et al. 2006).

Many dietary-related factors, such as high blood glucose, overconsumption, high cholesterol, alcohol, and low consumption of fruit and vegetables contribute to an increasing global burden of disease (WHO 2009). Globally, in 2016, a suboptimal diet accounted for $9.6 \%$ of DALYs and $18.8 \%$ of all deaths (Abajobir et al. 2017). That is why, according to the Food and Agriculture Organization (FAO), a sustainable diet should, among other things, be environmentally friendly and contribute toward health (Food and Agriculture Organization 2010). These criteria should be considered simultaneously since an environmentally friendly diet may not necessarily benefit health and vice versa. For example, dietary scenarios that primarily aim to lower dietary GHG emissions do not always result in improvements in nutritional quality or health outcomes (Payne et al. 2016). In addition, no direct association was observed between diet-related GHG emissions and mortality risk in a previous study (Biesbroek et al. 2014). However, adhering to a vegetarian or Mediterranean-style dietary pattern has been shown to be associated with lower environmental impacts and better health (Aleksandrowicz et al. 2016; Hallström et al. 2015; Nelson et al. 2016).

Dietary patterns based on nutritional guidelines from the WHO or national health councils are examples of a priori defined diets (Kromhout et al. 2016; WHO 2003). Besides a priori dietary patterns, several statistical models can derive and identify posteriori dietary patterns actually present based on population food intake information (Ocké 2013). Examples of these models are principle component analysis (PCA) or cluster analysis (CA) (Hearty and Gibney 2009; Newby and Tucker 2004; Stricker et al. 2013). Both a priori and a posteriori techniques have been combined in a relatively new method: reduced rank regression (RRR) (Hoffmann et al. 2004). When combining dietary information with known biomarkers for a disease, RRR was able to derive dietary patterns that showed stronger associations with a particular disease than PCA-based patterns (Hoffmann et al. 2004; Nettleton et al. 2007; Schulze and Hoffmann 2006).

This hybrid approach is partly theoretically driven, by using variables that are relevant to answer the research question, but still identifies dietary patterns based on the data. For our study, we used a priori knowledge on the healthiness of diets and environmental effects of foods to identify dietary patterns that could potentially be more sustainable and healthy. As far as we know, RRR has only been applied with biomarkers of disease or nutrient intake as response variables but not with an overall dietary index based on recommendations for a healthy diet (Ocké 2013), let alone in combination with an indicator of environmental impact.

In this study, we will investigate the association between the current Dutch dietary guidelines and their environmental impact (a priori). Secondly, we will investigate which dietary patterns are present in our study population that might be beneficial for health and the environment (hybrid approach). 


\section{Subjects and methods}

\subsection{Study population}

The European Prospective Investigation into Cancer-Netherlands (EPIC-NL) cohort consists of 40,011 subjects of EPIC-Prospect (Boker et al. 2001) and EPIC-MORGEN (Blokstra et al. 2005; Verschuren et al. 2008) both with inclusion of participants from which data were collected between 1993 and 1997. Both studies comply with the Declaration of Helsinki (Beulens et al. 2010).

Participants without dietary information at baseline were excluded $(n=218)$ for the current analysis. To exclude dietary over and under reporters, participants in the highest and lowest $0.5 \%$ of the ratio of reported energy intake to basal metabolic rate were also excluded $(n=$ $400)$. Participants with a self-reported history of cancer $(n=1645)$, diabetes $(n=793)$, myocardial infarction $(n=531)$, or stroke $(n=463)$ at baseline were excluded to include the same population as our previous publications (Biesbroek et al. 2014; Biesbroek et al. 2017). After these exclusions, 36,209 participants remained for analysis.

\subsection{Dietary assessment}

Usual daily dietary intake was estimated by a 178-item food frequency questionnaire that has been validated against 12 24-h recalls and biomarkers in 24-h urine and blood samples (Ocke et al. 1997a; Ocke et al. 1997b). Spearman rank correlation coefficients based on estimates of the FFQ and 24-h recalls were 0.51 for potatoes, 0.36 for vegetables, 0.68 for fruits, 0.39 for meat, 0.69 for dairy, 0.76 for sugar and sweet products, and 0.52 for biscuits and pastry in men. Similar results were obtained for women. Energy intake and daily nutrient intakes were estimated using the Dutch Food Composition Table (NEVO-table 1996). We grouped the food items into 35 food groups (Supplemental table 1). For each of the 35 food groups, intakes were presented as the percentage energy they contributed to total energy intake.

\subsection{Assessment of healthiness of diets}

We calculated the Dutch Healthy Diet index 2015 score as an indicator of the healthiness of the diet (Looman et al. 2017) in our study population. A proportional score between 0 and 10 was assigned to each of the 15 recommendations (Supplemental Table 2). Some recommendations require a minimal level of intake. For example, for fruit, it is recommended to eat at least $200 \mathrm{~g}$ per day. An intake equal to or above this level received the maximum score of 10 points, gradually decreasing to an intake level of 0 which received 0 points. For other foods, the guidelines recommend a maximum intake. For example, for salt, it is recommended to consume a maximum of $6 \mathrm{~g}$ per day ( $2.4 \mathrm{~g}$ sodium). An intake below this level received the maximum score of 10 points, gradually decreasing to a score of 0 points at the reference value (twice the recommended level of intake) and above. In our FFQ, added salt was not included. Previously, added salt was estimated to be $20 \%$ (Van Rossum et al. 2011), and subsequently the upper limit was set at $4.8 \mathrm{~g}$ of salt (1.9 $\mathrm{g}$ of sodium). For dairy, an optimal intake is recommended (2-3 portions per day). Consumption of 2-3 portions received 10 points, gradually decreasing to an intake level of 0 which received 0 points. When intake was higher than 3 portions, the score also gradually decreased to a score of 0 points at 5 portions per day or more. For some food groups, it is recommended to replace one type of food with another. 
For example, it is recommended to replace butter and hard fats with margarines and oils. For this type of recommendation, we created a ratio by dividing the intake of the recommended food by the intake of the replaced food. When the oils/fats ratio was higher than 13, a score of 10 points was received, gradually decreasing to 0 points when the ratio was lower than 0.6 (Looman et al. 2017). For coffee, the recommendation is to consume filtered instead of unfiltered coffee. However, in our population, information was not available on the type of coffee consumed, so this item was omitted from our calculation of the DHD15-index.

\subsection{Assessment of the environmental impact of diets}

Blonk Consultants assessed the environmental impact of food items consumed by the Dutch population (Marinussen et al. 2012). As a proxy for environmental impact, greenhouse gas (GHG) emissions were calculated using life cycle assessments (LCA) and expressed as kilogram $\mathrm{CO}_{2}$-equivalents per day. These LCAs included all steps from production, transport, and preparation. Food losses during production, retail, transportation, and consumption are taken into account in the LCA models. The impacts of processing this waste (composting, byproducts, etc.) are allocated to the products that benefit from this compost and other byproducts. We use weighted averages per food group which considers the proportion of imported/Dutch products and different production methods. The LCA data, version 2014, was linked to the EPIC-NL FFQ data to calculate daily GHG emissions associated with the usual diet. A more extensive description of the calculation of environmental impact of the diet in EPIC-NL has been published previously (Biesbroek et al. 2014).

\subsection{Lifestyle and anthropometric variables}

At baseline, study participants completed a general standardized structured questionnaire. Blood pressure, weight, and height were measured by trained staff according to standardized protocols (Beulens et al. 2010). Physical activity was assessed using a validated questionnaire (Haftenberger et al. 2002) and classified according to the Cambridge Physical Activity Index (CPAI) with single imputed data for missing values $(n=4930)$ (Pols et al. 1997). The CPAI has four categories, i.e., inactive, moderately inactive, moderately active, and active. Cigarette smoking was categorized as current, former, and never smoker. Educational level was classified as low (lower vocational training or primary school), medium (intermediate vocational training or secondary school), or high (higher vocational training or university).

\subsection{Statistical analysis}

Our first aim was to assess the association between the current Dutch guidelines and environmental impact of the diet. We assessed the association between the DHD15-index, which measures adherence to the Dutch guidelines, and GHG emissions. A linear regression model was created including total dietary GHG emissions as the dependent variable and the DHD15index score as the independent variable, adjusted for age and sex.

Our second aim was to derive dietary patterns in our population based on health and the environment. We used RRR to extract in our population specific dietary patterns based on both the variations in the DHD15-index score and dietary GHG emissions. RRR was applied using the PROC PLS procedure in SAS. The predictor variables were the food groups in percentage of energy and response variables were the DHD15-index score and daily dietary GHG 
emissions. The hybrid RRR model derives dietary patterns, i.e., correlations of food groups that explain the variation in the response variables. By definition, RRR retains a number of patterns that are equal to the number of response variables. The dietary pattern labeling was based on the food groups contributing most to the pattern. Food groups were considered important to a pattern when their factor loading was $>0.20$. Each participant receives a pattern score for both of the derived patterns. The pattern scores were divided into quartiles. Participants in quartile 4 (Q4) of a pattern score were considered as highest adherents to that pattern. The participants in Q1 of a pattern score consume a diet inverse to that of the labeled pattern. We used general linear models to calculate differences in mean DHD15-index score and GHG emissions between the different quartiles of the two dietary patterns with adjustment for age, sex, and energy intake. In order to calculate the $p$ value for the difference in GHG emissions and DHD15-index score between the Q4s of both patterns and between the Q4s and the cohort mean, we rearranged the data to a long format in which participants can have more than one observation. This was done because participants can be adherents to both patterns. PROC GENMOD was used to compare the environmental impact and DHD15-index score between the patterns.

All statistical analyses were performed using SAS software (version 9.4, SAS Institute Inc., Cary, NC, USA). A two-sided $p$ value of $<0.05$ was considered statistically significant.

\section{Results}

In our sub-sample of the EPIC-NL cohort, $73.7 \%$ of the participants are female, with average age for participants of 49 years at baseline (Table 1). The average BMI is $25.6 \mathrm{~kg} / \mathrm{m}^{2}$, about one third of the population are current smokers, and about one fifth have an education at higher vocational training or university level. Almost half of participants are classified as physically active. The DHD15-index score is on average 75.5 (SE: 0.1) points out of a maximum score of 140 points. Scores range from 18.2 to 130.3 points on the DHD15-index. The mean adjusted dietary GHG emissions is 4.1 (SE: $0.01) \mathrm{kg} \mathrm{CO}$-eq/day in our population.

\subsection{DHD15-index, single recommendations, and GHG emissions}

The populations' median consumption of the food groups from the DHD15-index recommendations and related GHG emissions are presented in Fig. 1. The average GHG emissions per kilogram product of the food groups considered in the guidelines shows foods with the relative highest environmental impact are all animal-based (Supplemental fig. 1). Food groups like fruits and vegetables, nuts, tea, and legumes, that are also included in the DHD15-index, have relatively low GHG emissions per kilogram food. Since the intake of these foods is low in our population (Table 1), there is potential to increase the healthiness of the diet with a relatively small increase in GHG emissions.

When examining the association between DHD15-index scores and dietary GHG emissions, the crude scatterplot (Supplemental fig. 2) illustrates that with similar total DHD15index scores the GHG emissions of the diet vary greatly, but higher scores tend to be associated with lower GHG emissions. The linear regression model shows that after adjusting for age and sex, for every 10 points increase on the DHD15-index, dietary GHG emissions decrease by $0.2(\mathrm{SE} 0.004, p<0.0001) \mathrm{kg} \mathrm{CO}$-eq/day. 
Table 1 Characteristics (mean (SE)) of adherent of the reduced rank regression derived "Prudent" and "Dairybased" dietary patterns

\begin{tabular}{|c|c|c|c|c|c|}
\hline & \multirow[t]{2}{*}{ Mean EPIC-NL } & \multicolumn{2}{|c|}{ "Plant-based Pattern" } & \multicolumn{2}{|c|}{ "Dairy-based Pattern" } \\
\hline & & Quartile 1 & Quartile 4 & Quartile 1 & Quartile 4 \\
\hline Participants & 36,209 & 9052 & 9052 & 9052 & 9052 \\
\hline Age (years) & $48.6(0.1)$ & $45.6(0.1)$ & $51.6(0.1)$ & $46.3(0.1)$ & $50.6(0.1)$ \\
\hline$\%$ Males & 26.3 & 39.6 & 19.3 & 32.9 & 20.3 \\
\hline Body mass index $\left(\mathrm{kg} / \mathrm{m}^{2}\right)$ & $25.6(0.02)$ & $26.3(0.04)$ & $24.9(0.04)$ & $25.6(0.04)$ & $25.6(0.04)$ \\
\hline$\%$ Current smokers & 30.7 & 46.7 & 17.9 & 39.1 & 24.7 \\
\hline$\%$ Physically active (CPAI) ${ }^{\mathrm{a}}$ & 42.0 & 40.8 & 43.1 & 39.8 & 43.1 \\
\hline Energy intake (kcal/day) & $2063(2.7)$ & $2172(5.6)$ & $1903(5.5)$ & $1910(5.3)$ & $2182(5.3)$ \\
\hline High education $^{\mathrm{b}}$ & $20.9 \%$ & 16.5 & 24.5 & 18.8 & 25.1 \\
\hline \multicolumn{6}{|l|}{ Dietary intake } \\
\hline \multicolumn{6}{|l|}{ Plant-based foods } \\
\hline Potatoes (g) & $104(0.3)$ & $113(0.7)$ & $95(0.7)$ & $119(0.6)$ & $88(0.6)$ \\
\hline Vegetables (g) & $131(0.3)$ & $107(0.5)$ & $160(0.5)$ & $136(0.5)$ & $126(0.5)$ \\
\hline Legumes $(\mathrm{g})$ & $9(0.1)$ & $7(0.1)$ & $13(0.1)$ & $9(0.1)$ & $10(0.1)$ \\
\hline Fruits $(\mathrm{g})$ & $196(0.7)$ & $123(1.3)$ & $279(1.3)$ & $168(1.4)$ & $222(1.4)$ \\
\hline Nuts and seeds (g) & $9(0.1)$ & $5(0.1)$ & $13(0.1)$ & $7(0.1)$ & $12(0.1)$ \\
\hline Cereals $(g)$ & $198(0.4)$ & $172(0.7)$ & $214(0.7)$ & $216(0.7)$ & $178(0.7)$ \\
\hline Sugar and confectionary $(\mathrm{g})$ & $45(0.2)$ & $38(0.3)$ & $47(0.3)$ & $50(0.3)$ & $38(0.3)$ \\
\hline Cake and pie $(\mathrm{g})$ & $30(0.1)$ & $20(0.2)$ & $38(0.2)$ & $30(0.2)$ & $28(0.2)$ \\
\hline Other non-alcoholic drinks (g) & $382(1.8)$ & $365(3.8)$ & $423(3.8)$ & $384(3.7)$ & $398(3.6)$ \\
\hline Sweetened beverages $(\mathrm{g})$ & $203(1.0)$ & $254(2.0)$ & $174(2.0)$ & $257(1.9)$ & $164(1.9)$ \\
\hline Coffee and tea $(\mathrm{g})$ & $847(1.8)$ & $811(3.8)$ & $876(3.8)$ & $914(3.7)$ & $787(3.7)$ \\
\hline Beer $(g)$ & $84(1.1)$ & $168(2.3)$ & $58(2.2)$ & $87(2.2)$ & $75(2.2)$ \\
\hline Wine $(g)$ & $52(0.5)$ & $68(1.0)$ & $33(1.0)$ & $51(0.9)$ & $54(0.9)$ \\
\hline Other alcoholic drinks (g) & $7(0.1)$ & $14(0.3)$ & $3(0.2)$ & $7(0.2)$ & $7(0.2)$ \\
\hline Condiments $(\mathrm{g})$ & $20(0.1)$ & $20(0.2)$ & $20(0.2)$ & $22(0.2)$ & $17(0.2)$ \\
\hline Soups $(g)$ & $72(0.4)$ & $77(0.8)$ & $67(0.8)$ & $85(0.8)$ & $57(0.8)$ \\
\hline Miscellaneous (g) & $9(0.1)$ & $9(0.1)$ & $11(0.1)$ & $11(0.1)$ & $7(0.1)$ \\
\hline \multicolumn{6}{|l|}{ Animal-based foods } \\
\hline Dairy $(\mathrm{g})$ & $387(1.4)$ & $336(2.9)$ & $408(2.8)$ & $256(2.6)$ & $523(2.6)$ \\
\hline Cheese (g) & $37(0.1)$ & $35(0.3)$ & $38(0.3)$ & $25(0.3)$ & $55(0.3)$ \\
\hline Red meat (g) & $61(0.2)$ & $79(0.3)$ & $41(0.3)$ & $56(0.3)$ & $63(0.3)$ \\
\hline Poultry $(\mathrm{g})$ & $12(0.1)$ & $12(0.1)$ & $12(0.2)$ & $13(0.1)$ & $12(0.1)$ \\
\hline Processed meat $(\mathrm{g})$ & $31(0.1)$ & $51(0.3)$ & $18(0.3)$ & $32(0.3)$ & $30(0.3)$ \\
\hline Fish $(\mathrm{g})$ & $11(0.1)$ & $8(0.1)$ & $14(0.1)$ & $9(0.1)$ & $12(0.1)$ \\
\hline $\operatorname{Egg}(g)$ & $16(0.1)$ & $18(0.2)$ & $15(0.2)$ & $19(0.1)$ & $14(0.1)$ \\
\hline
\end{tabular}

Continuous variables are presented as mean and standard error corrected for age, gender, and energy intake. Categorical variables are presented as percentage, also corrected for age, gender, and energy intake

${ }^{a}$ Cambrigde Physical Activity Index (four categories: inactive, moderate inactive, moderate active, active)

${ }^{\mathrm{b}}$ Higher vocational training or university

\subsection{Dietary patterns including both health and environmental effects}

With RRR, two dietary patterns were identified. The first pattern ("Plant-based Pattern") explained $40.5 \%$ of the variance in GHG emissions and DHD15-index scores and $6.5 \%$ of the variance in food intake. For the second pattern ("Dairy-based Pattern"), these were 6.4 and $2.9 \%$, respectively. In the "Plant-based Pattern," Q4 is characterized by a high consumption of fruits, boiled and raw vegetables, soy products, legumes, cake and pies, and low fat fish, and a low consumption of fries, sugar-containing sodas, other alcoholic beverages, red meat, and 


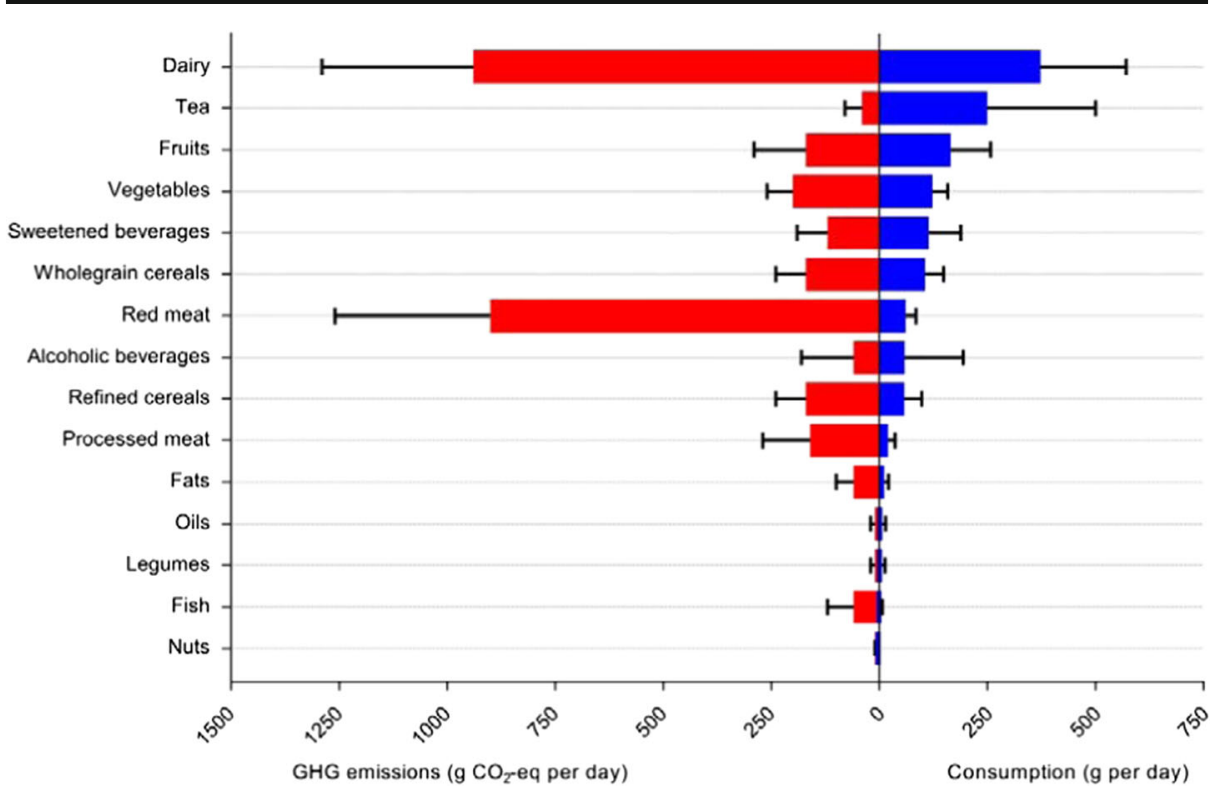

Fig. 1 Median (interquartile range) consumption and associated greenhouse gas (GHG) emissions of the food groups in the Dutch Healthy Diet index 2015 sorted by consumption

processed meat (Fig. 2). The inverse dietary pattern (Q1 of the pattern score) of the "Plantbased Pattern" could be labeled as a "Western Pattern" due to the high amount of fries, sugarcontaining sodas, other alcoholic beverages, red meat, and processed meat. In the "Dairybased Pattern," Q4 shows high consumption of cheese, low fat and high fat milk products, nuts, and seeds, and low consumption of coffee and tea, sugar-containing sodas, low-fiber bread, soy products, fats, and savory sauces.

Comparing Q4 to Q1 of adhering to the "Plant-based Pattern," thus comparing the "Plant-based Pattern" to the "Western Pattern," a statistically significant $49.9 \%$ higher DHD15-index score is observed (89.8 versus 59.9 points) after adjusting for age, sex, and energy intake (Fig. 3). In contrast, GHG emission is significantly 7.7\% lower in Q4 than in Q1 (3.96 versus $4.29 \mathrm{~kg} \mathrm{CO}_{2}$-eq/day). With increasing adherence to the "Dairybased Pattern" both a significantly higher DHD15-index score of 8.6\% (77.9 versus 71.7 points) and GHG emission of $15.4 \%$ (4.43 versus $3.84 \mathrm{~kg} \mathrm{CO}_{2}$-eq/day) are observed.

When we compare the highest adherents of the two dietary patterns (participants in Q4 of the factor score), it shows that those adhering to the "Plant-based Pattern" are more likely to be women, less likely to be a current smoker and consume fewer calories (adjusted for age and gender) than those adhering to the "Dairy-based Pattern" (Table 1). DHD15-index scores are higher $(89.8$ versus 77.9 points, $p<0.0001)$ and GHG emissions are lower (3.96 versus $4.43 \mathrm{~kg} \mathrm{CO}_{2}$-eq/day, $p<0.0001$ ) in Q4 of the "Plant-based Pattern" than in Q4 of the "Dairy-based Pattern." For both derived dietary patterns, adherents (Q4) have a higher DHD15-index score compared to the observed average EPIC-NL diet (Fig. 3, both $p<0.0001$ ). However, GHG emissions are lower in adherents to the "Plant-based Pattern" and higher in adherents of the "Dairy-based Pattern" compared to the mean diet (both $p<0.0001$ ). 


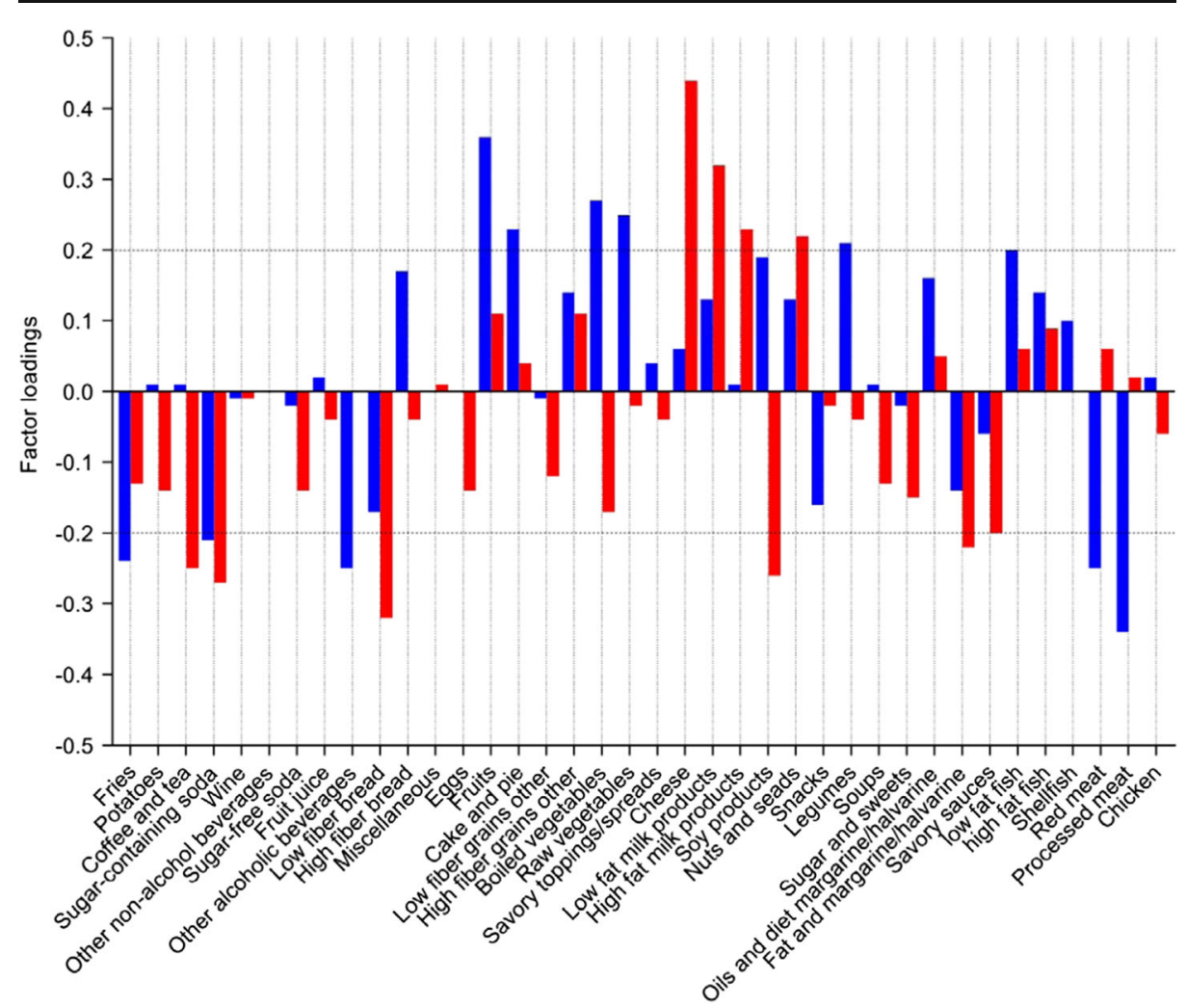

Fig. 2 Factor loadings of the food groups on two dietary patterns derived with reduced rank regression explaining the variance in greenhouse gas (GHG) emissions and Dutch Healthy Diet index 2015 (DHD15index) scores. Food groups with factor loadings greater than $|0.20|$ are considered important contributors to a dietary pattern. The red pattern is labeled "Dairy-based Pattern" and the blue pattern "Plant-based Pattern"

\section{Discussion}

In our population, increasing compliance to the Dutch dietary guidelines is associated with lower dietary greenhouse gas emissions. On average, for every 10 points higher score on the DHD15-index (0 to 140 points), dietary GHG emissions were $0.2 \mathrm{~kg} \mathrm{CO}_{2}$ equivalents per day lower. This analysis included an a priori determined healthy dietary pattern and the finding confirms recent review study results (Aleksandrowicz et al. 2016; Nelson et al. 2016).

Based on the variation in dietary intake within the population, we derived two dietary patterns using the hybrid RRR approach. We derived a "Plant-based" (fruits and vegetables, fish, legumes, and soy products) and its inverse dietary pattern that could be labeled a "Western Pattern." The second dietary pattern was labeled as "Dairy-based" (cheese, low and high fat milk products, nuts, and seeds). Consumers in the highest quartile of the "Plant-based pattern" had a 17.8\% higher adjusted DHD15-index score and $2.5 \%$ lower GHG emissions compared to the average EPIC-NL diet. Shifting the population from an average diet toward a diet similar to the diet in the upper quartile of the "Plant-based Pattern" would therefore be a first step toward a more sustainable diet. 


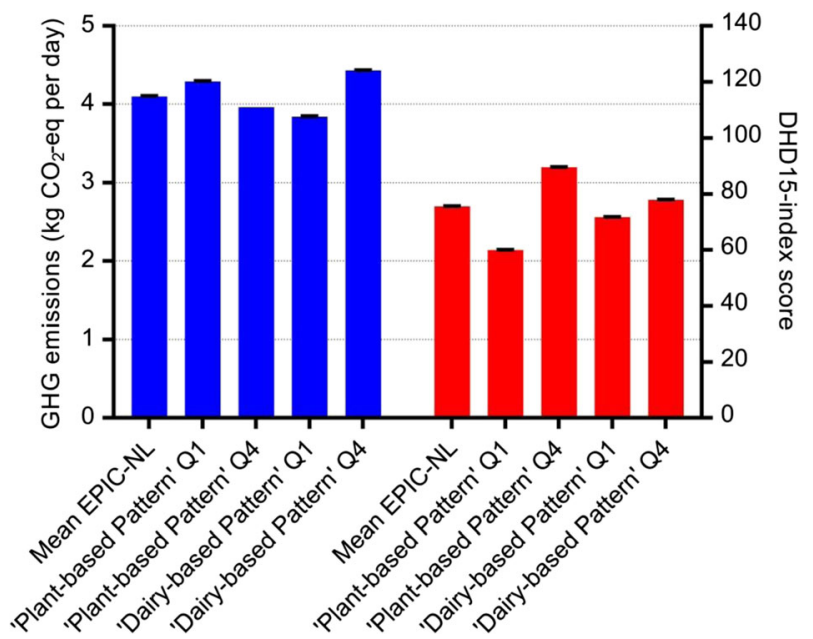

Fig. 3 Mean (standard error) greenhouse gas (GHG) emissions and Dutch Healthy Diet index 2015 (DHD15index) score of the highest and lowest quartile of adherence of the two dietary patterns derived with Reduced Rank Regression compared to the cohort mean. Mean and standard error corrected for age, gender, and energy intake

The "Dairy-based Pattern" was the less dominant pattern and has an interesting trade-off between health and environmental impact; a similar score on the DHD15-index was observed in consumers in quartile 4 of this pattern compared to the average population, but at the expense of a higher environmental impact.

Currently, only a limited number of dietary guidelines across the world include sustainability aspects, mainly in appendices of the main guidelines (Food and Agriculture Organization 2010). For example, the Swedish national food agency published additional guidelines on meat replacement, storage, and prevention of food waste, and recommended eating less sweets, cakes, and cookies because of a their low nutritional contribution and impact on the environment (Livsmedelsverket (Swedish National Food Agency) 2015). By including environmental impact in our analysis, the results can be used to investigate how the Dutch dietary guidelines can be adapted to also include sustainability aspects. Although the overall recommendation of the Dutch health council to consume more plant-based rather than animal-based foods could be considered as more sustainable, this recommendation was based on evidence about diet-disease associations (Kromhout et al. 2016). Rephrasing this statement, to "Follow a dietary pattern that involves eating more plant-based and less animal-based foods would be beneficial for health and would reduce the environmental impact of our diet" would explicitly combine both aspects for consumers. For dairy and fish, the food specific guidelines could be expanded taking into account guidance on environmental aspects since consumers might perceive recommendations for these foods as "more is better." Although a high dairy intake (above the recommended 2-3 portions per day) may not be associated with increased health risks (Gezondheidsraad 2015), the food group has a high environmental impact, as observed in our "Dairy-based Pattern." For fish, the largest health gain can be achieved when shifting from "no fish" to "fish once per week." There seems to be no additional health effect with higher consumption (Kromhout et al. 2016). However, a higher consumption would negatively affect current fish stocks which are already under pressure (Sumaila et al. 2007). 
Besides dietary quality, dietary guidelines could also focus more on the total number of calories of a diet. Consuming adequate numbers of calories would be more beneficial for both health (weight) and the environment (less food needed) in our population since the mean BMI is just over $25 \mathrm{~kg} / \mathrm{m}^{2}$. We observed that high adherents of the "Plant-based Pattern" consumed fewer calories than the average EPIC-NL population (1903 versus 2063 cal per day). In our analyses, we adjusted the models for energy intake to be able to compare the environmental impact and quality of the diet more objectively. Without adjusting for energy intake, the difference in GHG emission between the highest and lowest quartile of the "Plant-based Pattern" would be $10 \%$ (data not shown) compared to a moderate $2.5 \%$ after adjustment. In overconsuming Western populations, this clearly shows the importance of adopting a diet that is in line with the energy requirement as well as from an environmental point of view.

Part of the sustainable diets definition of the FAO is that these patterns should also be socially acceptable to make the necessary changes feasible (Food and Agriculture Organization 2010). Because the derived data-driven RRR dietary patterns are based on actual dietary intake present within our population, we might assume these patterns are culturally acceptable.

Other studies, using linear modeling of diets without applying possible consumer constraints (and thus including diets that differ considerably from the current one or diets with very limited variety in food items) show possible reductions in dietary GHG emissions as high as 70-80\%. However, significant smaller changes are observed when these constraints are taken into account (Aleksandrowicz et al. 2016). Green et al. used an optimization tool to model the current UK diet so that it meets the WHO guidelines (Green et al. 2015). They observed that adherence would require several major changes to the current diet, of which a lower consumption of meat, dairy and eggs (particularly in men), and soft drinks were the most important. This WHO-UK diet would result in a $17 \%$ reduction in GHG emissions. Applying more drastic dietary changes such as leaving out meat or fish would result in much larger reductions in GHG emissions (20-30\% (Aleksandrowicz et al. 2016)) than from consuming our "Plant-based Pattern" (3\%). This implies two things. First, to achieve small reductions in GHG emissions, advised diets could be built with the current diets as a starting point, like in our study, to make it feasible for people to slowly change their habits. Second, we need to acknowledge that if we aim for larger reductions in GHG emissions, cultural change is needed in which the sustainable dietary pattern becomes a new standard. Such a cultural change would be much harder to achieve, but is required to adopt new sustainable and healthy dietary patterns. Maintaining existing dietary patterns may not be enough to reach the true potential of dietary change (Dagevos and Voordouw 2013; Gonzalez Fischer and Garnett 2016; Green et al. 2015).

Reduced rank regression is a relatively new method to derive dietary patterns (Ocké 2013). Compared to PCA, for example, RRR derives patterns that are only slightly different but show stronger associations with diseases (DiBello et al. 2008; Hoffmann et al. 2005; Nettleton et al. 2007). A previous study with EPIC-NL data reported that PCA derived two dietary patterns: a "Prudent" and a "Western" pattern (Stricker et al. 2013). The prudent pattern resembles a kind of "Plant-based Pattern" and its opposite the "Western Pattern," whereas the "Dairy-based Pattern" was not derived. The added information of the response variables thus seem to create more specific dietary patterns. The PCA patterns of Stricker et al. (2013) together explained $20.8 \%$ of the variance in food groups versus $9.4 \%$ of our RRR-based diet patterns. Hoffman 
et al. (2005) produced similar differences in explained variance between PCA (19.7\%) and RRR (10.5\%). Similar comparison studies also showed that in general PCA-derived patterns explain more variance of the food groups but explain less of the variance in response variables (Hoffmann et al. 2005; Hoffmann et al. 2004). Our first RRR pattern explained $40.5 \%$ of the response variable variation, which is in line with results from other studies (Biesbroek et al. 2015; Hoffmann et al. 2005; Hoffmann et al. 2004), but clearly leaves a proportion of the variance unexplained. Other factors, such as socioeconomic status, age, or gender might also impact GHG emissions of the diet and dietary quality.

Strengths of this study are that we used both dietary and environmental impact data from the same population. The EPIC-NL study is a large cohort in a representative sample of the Dutch population. The limitations of this study also deserve discussion. This cross-sectional analysis of baseline data in our cohort is based on a FFQ which has been administered between 1993 and 1997. Dietary habits of our participants have most likely changed over time and thus the patterns derived in our study may not truly reflect current diets in the Netherlands. During the last 5 years in the Netherlands, the consumption of potatoes, fats and oils, alcoholic beverages, dairy products, cakes and biscuits, and meat decreased (Van Rossum et al. 2016). Consumption of vegetables, and cereals and bread remained stable and use of non-alcoholic drinks and condiments and sauces increased. In addition, most Dutch adults do not meet the current dietary guidelines, just like in our cohort (Van Rossum et al. 2017). We believe that even though dietary habits may have changed, our current findings help to build more evidence on how a sustainable and healthy dietary pattern may or should look like. The indicators for environmental impact are based on Dutch life cycle analysis data and therefore apply to a Dutch setting only. Our results for environmental impact of the dietary patterns may therefore not be directly extrapolated to other countries where production methods, productivity, fossil energy use, in- and export, and ways of transport may differ. However, the average GHG emissions of the diet seem comparable to previous studies (Aleksandrowicz et al. 2016; Nelson et al. 2016).

In conclusion, when deriving dietary patterns based on health and environmental aspects of the diet, a "Plant-based" and a "Dairy-based" pattern were present in our population. Of these, a plant-based diet with low amounts of meat, sugar-containing sodas, and alcoholic beverages benefits health as well as the environment in a socially acceptable way. Our study provides information on how to incorporate sustainability aspects in dietary guidelines.

Acknowledgments We would like to thank Marjolein Geurts, MSc (RIVM), and Kathryn Beck, PhD (Massey University, New Zealand), for proofreading our manuscript.

Author's contributions SB, WMMW, and EHMT designed the research. SB conducted the research and analyzed data. JB, YTS, and IS provided valuable input on the manuscript. All authors read and approved the final manuscript.

Funding This project was funded by a research grant from the Strategic Program of the RIVM, Project code: S133006.

\section{Compliance with ethical standards}

Conflict of interest The authors declare that they have no conflict of interest.

Abbreviations CI, Confidence interval; DHD15-index, Dutch healthy diet 2015 index; EPIC-NL, European Prospective Investigation into Cancer and Nutrition - Netherlands; FAO, Food and Agriculture Organization; FFQ, Food frequency questionnaire; GHG, Greenhouse gas; RRR, Reduced rank regression; WHO, World Health Organization 
Open Access This article is distributed under the terms of the Creative Commons Attribution 4.0 International License (http://creativecommons.org/licenses/by/4.0/), which permits unrestricted use, distribution, and reproduction in any medium, provided you give appropriate credit to the original author(s) and the source, provide a link to the Creative Commons license, and indicate if changes were made.

\section{References}

Abajobir AA et al (2017) Global, regional, and national comparative risk assessment of 84 behavioural, environmental and occupational, and metabolic risks or clusters of risks, 1990\&\#x2013;2016: a systematic analysis for the Global Burden of Disease Study 2016. Lancet 390:1345-1422. https://doi.org/10.1016 /S0140-6736(17)32366-8

Aleksandrowicz L, Green R, Joy EJM, Smith P, Haines A (2016) The impacts of dietary change on greenhouse gas emissions, land use, water use, and health: a systematic review. PLoS One 11:e0165797. https://oi. org/10.1371/journal.pone.0165797

Beulens JWJ et al (2010) Cohort profile: the EPIC-NL study. Int J Epidemiol 39:1170-1178

Biesbroek S et al (2014) Reducing our environmental footprint and improving our health: greenhouse gas emission and land use of usual diet and mortality in EPIC-NL: a prospective cohort study. Environ Health $13: 27$

Biesbroek S, van der AD, Brosens MC, Beulens JW, Verschuren WM, van der Schouw YT, Boer JM (2015) Identifying cardiovascular risk factor-related dietary patterns with reduced rank regression and random forest in the EPIC-NL cohort. Am J Clin Nutr 102:146-154

Biesbroek S et al (2017) Does a better adherence to dietary guidelines reduce mortality risk and environmental impact in the Dutch sub-cohort of the European prospective investigation into cancer and nutrition? $\mathrm{Br} \mathrm{J}$ Nutr 118:69-80. https://doi.org/10.1017/S0007114517001878

Blokstra A, Smit H, Bueno de Mesquita H, Seidell J, Verschuren W (2005) Monitoring of risk factors and health in the Netherlands (MORGEN-cohort) 1993-1997. Lifestyle and risk factors: prevalences and trends (in Dutch). RIVM report 263200008, Bilthoven

Boker LK et al (2001) Prospect-EPIC Utrecht: study design and characteristics of the cohort population. Eur J Epidemiol 17:1047-1053

Dagevos H, Voordouw J (2013) Sustainability and meat consumption: is reduction realistic? Sustain Sci Pract Policy 9:60-69

DiBello JR, Kraft P, McGarvey ST, Goldberg R, Campos H, Baylin A (2008) Comparison of 3 methods for identifying dietary patterns associated with risk of disease. Am J Epidemiol 168:1433-1443. https://oi. org/10.1093/aje/kwn274

Food and Agriculture Organization (2010) International scientific symposium. Biodiversity and Sustainable Diets United Against Hunger, Rome

Gezondheidsraad (2015) Zuivel - Achtergronddocument bij Richtlijnen goede voeding 2015. Gezondheidsraad, Den Haag

Gonzalez Fischer C, Garnett T (2016) Plates, pyramids, planet: developments in National Healthy and Sustainable Dietary Guidelines: a state of play assessment. The Food and Agriculture Organization of the United Nations and the Food Climate Research Network at the University of Oxford, Rome

Green $\mathrm{R}$ et al (2015) The potential to reduce greenhouse gas emissions in the UK through healthy and realistic dietary change. Clim Chang 129:253-265. https://doi.org/10.1007/s10584-015-1329-y

Haftenberger M et al (2002) Physical activity of subjects aged 50-64 years involved in the European Prospective Investigation into Cancer and Nutrition (EPIC). Public Health Nutr 5:1163-1178

Hallström E, Carlsson-Kanyama A, Börjesson P (2015) Environmental impact of dietary change: a systematic review. J Clean Prod 91:1-11

Hearty AP, Gibney MJ (2009) Comparison of cluster and principal component analysis techniques to derive dietary patterns in Irish adults. Br J Nutr 101:598-608

Hoffmann K, Schulze MB, Schienkiewitz A, Nothlings U, Boeing H (2004) Application of a new statistical method to derive dietary patterns in nutritional epidemiology. Am J Epidemiol 159:935-944

Hoffmann K, Boeing H, Boffetta P, Nagel G, Orfanos P, Ferrari P, Bamia C (2005) Comparison of two statistical approaches to predict all-cause mortality by dietary patterns in German elderly subjects. Br J Nutr 93:709716

Kromhout D, Spaaij C, De Goede J, Weggemans R (2016) The 2015 Dutch food-based dietary guidelines. Eur J Clin Nutr 70(8):869

Livsmedelsverket (Swedish National Food Agency) (2015) https://www.livsmedelsverket.se/en/food-habitshealth-and-environment/food-and-environment. Accessed May 2017 
Looman M et al. (2017) Development and evaluation of the Dutch Healthy Diet index 2015 public health nutrition: in press

Marinussen M, Kramer G, Pluimers J, Blonk H (2012) The environmental impact of our diet—an analysis based on de nutitional consumption survey of 2007-2010 (in Dutch, summary in English). Blonk Milieu Advies, Gouda

Moss RH et al (2010) The next generation of scenarios for climate change research and assessment. Nature 463: 747

Nelson ME, Hamm MW, Hu FB, Abrams SA, Griffin TS (2016) Alignment of healthy dietary patterns and environmental sustainability: a systematic review. Adv Nutr Int Rev J 7:1005-1025. https://doi.org/10.3945 /an.116.012567

Nettleton JA, Steffen LM, Schulze MB, Jenny NS, Barr RG, Bertoni AG, Jacobs DR Jr (2007) Associations between markers of subclinical atherosclerosis and dietary patterns derived by principal components analysis and reduced rank regression in the Multi-Ethnic Study of Atherosclerosis (MESA). Am J Clin Nutr 85: $1615-1625$

NEVO-table (1996) Dutch food composition table (NEVO_-Nederlandse Voedingsstoffenbestand-in Dutch). Zeist, NEVO Foundation

Newby PK, Tucker KL (2004) Empirically derived eating patterns using factor or cluster analysis: a review. Nutr Rev 62:177-203

Ocké MC (2013) Evaluation of methodologies for assessing the overall diet: dietary quality scores and dietary pattern analysis. Proc Nutr Soc 72:191-199. https://doi.org/10.1017/S0029665113000013

Ocke MC, Bueno-de-Mesquita HB, Goddijn HE, Jansen A, Pols MA, van Staveren WA, Kromhout D (1997a) The Dutch EPIC food frequency questionnaire. I. Description of the questionnaire, and relative validity and reproducibility for food groups. Int J Epidemiol 26:S37

Ocke MC, Bueno-de-Mesquita HB, Pols MA, Smit HA, van Staveren WA, Kromhout D (1997b) The Dutch EPIC food frequency questionnaire. II. Relative validity and reproducibility for nutrients. Int J Epidemiol 26: S49

Payne CL, Scarborough P, Cobiac L (2016) Do low-carbon-emission diets lead to higher nutritional quality and positive health outcomes? A systematic review of the literature. Public Health Nutr 19:2654-2661

Pols MA, Peeters P, Ocke MC, Slimani N, Bueno-de-Mesquita HB, Collette H (1997) Estimation of reproducibility and relative validity of the questions included in the EPIC Physical Activity Questionnaire. Int J Epidemiol 26:S181

Schulze MB, Hoffmann K (2006) Methodological approaches to study dietary patterns in relation to risk of coronary heart disease and stroke. Br J Nutr 95:860-869

Stricker M et al (2013) Dietary patterns derived from principal component-and k-means cluster analysis: longterm association with coronary heart disease and stroke. Nutr Metab Cardiovasc Dis 23:250-256

Sumaila UR, Khan A, Watson R, Munro G, Zeller D, Baron N, Pauly D (2007) The World Trade Organization and global fisheries sustainability. Fish Res $88: 1-4$

Tukker A et al (2006) Environmental impact of products (EIPRO) analysis of the life cycle environmental impacts related to the final consumption of the EU-25. European Commision, Joint Research Centre, Institute for Prospective Technological Studies, Brussels

United Nations (2015) Paris Agreement. Available from https://treaties.un.org/doc/Treaties/2016/02/20160215 \%2006-03\%20PM/Ch XXVII-7-d.pdf

United Nations General Assembly (2015) Resolution 70/1 Transforming our world: the 2030 Agenda for Sustainable Development United Nations, Available from https://documents-dds-ny.un. org/doc/UNDOC/GEN/N15/291/89/pdf/N1529189.pdf?OpenElement

Van Rossum C, Fransen H, Verkaik-Kloosterman J, Buurma-Rethans E, Ocké M (2011) Dutch National Food Consumption Survey 2007-2010: diet of children and adults aged 7 to 69 years RIVM rapport 350050006

Van Rossum CTM, Buurma-Rethans EJM, Vennemann FBC, Beukers M, Brants HAM, Boer EJD, Ocké MC (2016) The diet of the Dutch-results of the first two years of the Dutch National Food Consumption Survey 2012-2016. Bilthoven, RIVM Letter report 2016-0082

Van Rossum CTM, Buurma-Rethans EJM, Vennemann FBC, Beukers M, Brants HAM, Boer EJD, Ocké MC (2017) Voedselconsumptie in 2012-2014 vergeleken met de Richtlijnen goede voeding 2015. RIVM Rapport 2017-0095, Bilhoven

Verschuren W, Blokstra A, Picavet H, Smit H (2008) Cohort profile: the Doetinchem cohort study. Int J Epidemiol 37:1236-1241

WHO (2003) Diet, nutrition and the prevention of chronic diseases vol 2010. World Health Organization, Geneva WHO (2009) Global health risks-mortality and burden of disease attributable to selected major risk. World Health Organization, Geneva 